\title{
EVALUASI PENGUJIAN LANJUTAN KLON KARET IRR SERI 200 PADA MASA TANAMAN BELUM MENGHASILKAN
}

\author{
Further Trial Evaluation of IRR 200 Series Rubber Clones \\ in Immature Period
}

\author{
AIDI-DASLIN \\ Balai Penelitian Sungei Putih, Pusat Penelitian Karet \\ P.O. Box 1415, Medan 20001
}

Diterima tgl. 2 Pebruari 2011/Disetujui 3 Mei 2011

\begin{abstract}
Rubber breeding activities of fourth generation started in 1985 had produced clones of IRR 200 series. Promotion plot trials had resulted in some promising clones with high latex yielding, vigorous growth, resistance to diseases and good secondary characteristics. In order to get more comprehensive information, further trials of 12 clones were conducted in 2005 at two locations, viz. Serbangan estate, PT. Bakrie Sumatra Plantation and Aek Pamienke, PT.Socfin Indonesia in North Sumatra Province. The trials were arranged in a randomized block design. Observations were made on girth size over 2, 3, and 4 years, bark thickness, rings number, diameter of latex vessel and attack intensity of Colletotrichum, Oidium, Corynespora leaf fall diseases at 3 and 5 years. Based on the girth growth at 4 years, it was found that IRR 220 and IRR 211 had vigorous growth indicated by girth size of 44.9 and $51.0 \mathrm{~cm}$, respectively. Clone IRR 220 could be classified as stable at two locations, while IRR 211 was more adaptable to wet agroclimate locations. Based on bark thickness and latex vessels, clones IRR 208, IRR 211, IRR 215, IRR 217 and IRR 220 were predicted to have good potency as latex yielders. All of the clones were classified as moderately resistant to resistant to Colletotrichum, Oidium, Corynespora leaf fall diseases.
\end{abstract}

Keywords: Hevea brasiliensis, IRR 200 series, growth, secondary characteristics

\footnotetext{
Abstrak

Kegiatan pemuliaan tanaman karet generasi keempat yang dimulai tahun 1985 telah menghasilkan klon IRR seri 200. Dari hasil uji plot promosi telah diseleksi
}

beberapa klon harapan dengan daya hasil lateks tinggi, pertumbuhan jagur, resisten terhadap penyakit serta memiliki sifat-sifat sekunder penting yang baik. Untuk mendapatkan informasi yang lebih luas telah dilakukan uji lanjutan sebanyak 12 klon pada dua lokasi masing-masing di kebun Serbangan, PT. Bakrie Sumatra Plantation dan kebun Aek Pamienke, PT. Socfin Indonesia provinsi Sumatera Utara, yang dibangun tahun 2005 dengan menggunakan rancangan acak kelompok. Pengamatan pertumbuhan lilit batang dilakukan pada umur 2, 3, dan 4 tahun, tebal kulit, jumlah saluran, dan diameter pembuluh lateks masing-masing pada umur 5 tahun serta intensitas serangan penyakit gugur daun Colletotrichum, Oidium, dan Corynespora pada umur 3 dan 5 tahun. Dari pertumbuhan lilit batang pada umur 4 tahun, IRR 220 dan IRR 211 tergolong klon yang jagur (masing-masing lilit batang 44,9 dan $51,0 \mathrm{~cm}$ ). Klon IRR 220 tergolong stabil di dua lokasi pengujian, sedangkan IRR 211 adaptif di lokasi dengan iklim yang lebih basah. Berdasarkan ketebalan kulit dan pembuluh lateks, klon IRR 208, IRR 211, IRR 215, IRR 217 dan IRR 220 diprediksi berpotensi cukup baik sebagai penghasil lateks. Semua klon yang diuji tergolong agak resisten sampai dengan resisten terhadap penyakit gugur daun Colletotrichum, Oidium, dan Corynespora.

Kata kunci: Hevea brasiliensis, IRR seri 200, pertumbuhan, karakteristik sekunder.

\section{PENDAHULUAN}

Peningkatan produktivitas merupakan syarat utama agar komoditas karet tetap dapat bersaing dan menguntungkan di era globalisasi. Klon unggul menjadi salah satu 
komponen teknologi terpenting untuk mendukung kinerja dan kesinambungan industri perkaretan nasional yang efisien dan berdaya saing tinggi. Penanaman klon unggul secara signifikan meningkatkan produktivitas kebun serta efisiensi usaha, karena produksi yang tinggi akan menurunkan harga pokok. Kegiatan pemuliaan tanaman karet generasi keempat yang dimulai tahun 1985 telah menghasilkan sejumlah klon unggul harapan yang lebih produktif sebagai penghasil lateks tinggi, pertumbuhan jagur, resisten terhadap penyakit serta memiliki sifat-sifat sekunder penting yang baik (AidiDaslin, 2005).

Dalam program pemuliaan karet, kegiatan seleksi dan pengujian klon dilakukan secara bertahap, mulai dari uji keturunan (progeny test) pada populasi semaian hasil persilangan, uji plot promosi, uji pendahuluan, hingga pengujian multi lokasi (multi location test). Untuk menggali potensi keunggulan suatu klon, maka tahapan seleksi dari kegiatan pemuliaan tersebut perlu dilakukan secara sistematis dan berkesinambungan (Tan, 1987; Simmonds, 1989). Evaluasi pada tahap pengujian pendahuluan dan plot promosi klon IRR seri 200 telah menghasilkan beberapa klon unggul harapan baru yang memper-lihatkan berbagai potensi keunggulannya sebagai klon penghasil lateks dengan rata-rata potensi produksi karet kering sebesar 2,5 - 3,0 ton/ ha/th (Aidi-Daslin et al., 2009; Woelan et al., 2009).

Sehubungan dengan program pengem-bangan karet ke berbagai daerah dengan agroekosistem yang beragam, maka faktor lingkungan secara signifikan dapat mempengaruhi produktivitas klon. Sebagian klon unggul memiliki daya adaptasi yang luas, tetapi cukup banyak klon yang memper-lihatkan respons spesifik pada lingkungan yang tidak optimal. Hal ini disebabkan adanya pengaruh lingkungan fisik (tanah dan iklim) maupun lingkungan biologi (gangguan penyakit). Sejumlah klon unggul harapan terbaik IRR seri 200 yang diseleksi dari uji plot promosi dan uji pendahuluan, kemungkinan penampilannya akan optimal pada kondisi lingkungan pengujian tersebut, namun dapat berbeda jika dikembangkan pada lingkungan yang lain. Oleh karena itu diperlukan uji lanjutan untuk mengetahui kinerja klon pada berbagai lingkungan tumbuh. Pengujian ini penting karena adanya interaksi genotipe dan lingkungan, sebab tidak ada klon karet yang unggul pada semua lokasi penanaman (Aidi-Daslin et al., 1997). Artikel ini mengevaluasi kinerja sejumlah klon unggul harapan IRR seri 200 pada tahap pengujian lanjutan selama masa tanaman belum menghasilkan (TBM).

\section{BAHAN DAN METODE}

Pengujian lanjutan klon di-bangun pada tahun 2005, berlokasi di Kebun Serbangan, PT. Bakrie Sumatra Plantation dan Kebun Aek Pamienke, PT. Socfin Indonesia, keduanya berada di Sumatera Utara. Sebanyak 12 klon IRR seri 200 dan klon pembanding PB 260 diuji pada tiap lokasi dengan rancangan acak kelompok. Pengamatan terhadap pertum-buhan lilit batang dilakukan pada umur 2, 3, dan 4 tahun, sedangkan tebal kulit, jumlah saluran dan diameter pembuluh lateks masing-masing pada umur 5 tahun. Intensitas serangan penyakit gugur daun Oidium, Colletotrichum dan Corynespora diamati pada umur 3 dan 5 tahun dan dihitung berdasarkan rumus yang dikembangkan oleh Pawirosoemardjo (1999). Indeks stabilitas pertumbuhan tiap klon ditentukan dengan menghitung variasi (keragaman) antar lokasi (Steel dan Torrie, 1982). Deskripsi lengkap lokasi pengujian serta silsilah klon-klon yang diuji tertera pada Lampiran 1 dan 2 .

\section{HASIL DAN PEMBAHASAN}

\section{Pertumbuhan Lilit Batang}

Data rata-rata pertumbuhan lilit batang TBM di dua lokasi pengujian disajikan pada Tabel 1 dan 2. Berdasarkan hasil pengamatan menunjukkan bahwa pertumbuhan klon IRR seri 200 di lokasi Kebun Aek Pamienke diketahui lebih jagur dengan rata-rata lilit batang pada umur 2 tahun $(24,9 \mathrm{~cm}), 3$ tahun $(38,5 \mathrm{~cm})$ dan 4 tahun $(46,4 \mathrm{~cm})$, dengan koefisien keragaman (KK) berkisar 5,56 - 9,30\%, sedangkan di Kebun Serbangan memperlihatkan pertumbuhan lebih lambat yaitu rata-rata lilit batang pada umur 2 
Tabel 1. Pertumbuhan lilit batang klon IRR seri 200 di lokasi pengujian Aek Pamienke Table 1. Girth growth of IRR 200 series clones at Aek Pamienke trial location

\begin{tabular}{|c|c|c|c|c|}
\hline \multirow{2}{*}{$\begin{array}{l}\text { Klon } \\
\text { Clones }\end{array}$} & \multicolumn{3}{|c|}{$\begin{array}{l}\text { Lilit batang }(\mathrm{cm}), \text { pada umur } \\
\text { Girth }(\mathrm{cm}), \text { years }\end{array}$} & \multirow{2}{*}{$\begin{array}{c}\text { Pertambahan } \\
\text { lilit batang }(\mathrm{cm} / \mathrm{th}) \\
\text { Girth increment }(\mathrm{cm} / \mathrm{yr})\end{array}$} \\
\hline & $\begin{array}{l}2 \text { th } \\
2 y r\end{array}$ & $\begin{array}{l}3 \text { th } \\
3 y r\end{array}$ & $\begin{array}{l}4 \text { th } \\
4 y r\end{array}$ & \\
\hline IRR 205 & 22,2 & 41,7 & 46,7 (102) & $12,3(116)$ \\
\hline IRR206 & 21,2 & 36,7 & $42,6(93)$ & $10,7(101)$ \\
\hline IRR207 & 22,6 & 37,0 & $45,7(100)$ & $11,6(109)$ \\
\hline IRR208 & 22,1 & 34,4 & $41,4(90)$ & $9,7(92)$ \\
\hline IRR209 & 24,2 & 37,1 & $47,5(104)$ & $11,7(110)$ \\
\hline IRR 211 & 27,9 & 39,5 & $51,0(111)$ & $11,6(109)$ \\
\hline IRR215 & 26,3 & 40,8 & $49,5(108)$ & $11,6(109)$ \\
\hline IRR216 & 25,8 & 41,6 & $48,0(105)$ & $11,1(105)$ \\
\hline IRR 217 & 26,0 & 38,5 & $47,5(104)$ & $10,8(102)$ \\
\hline IRR2 19 & 28,5 & 39,2 & $46,1(101)$ & $8,8(83)$ \\
\hline IRR 220 & 26,7 & 40,4 & $47,0(103)$ & $10,8(102)$ \\
\hline IRR 221 & 25,6 & 35,2 & 44,6 (97) & $9,5(90)$ \\
\hline PB 260 & 24,6 & 38,3 & $45,8(100)$ & $10,6(100)$ \\
\hline Rata-rata (average) & 24,9 & 38,5 & 46,4 & 10,83 \\
\hline Min (minimum) & 21,2 & 34,4 & 41,4 & 8,80 \\
\hline Maks (maximum) & 28,5 & 41,7 & 51,0 & 12,30 \\
\hline KK (coeff. of variation) & 9,30 & 6,07 & 5,56 & 9,24 \\
\hline
\end{tabular}

Angka-angka di dalam kurung adalah persentase terhadap PB 260

Figures in brackets are percentage of $P B 260$

tahun $(14,0 \mathrm{~cm}), 3$ tahun $(25,4 \mathrm{~cm})$ dan 4 tahun $(37,2 \mathrm{~cm})$, dengan nilai KK berkisar $8,05-12,17 \%$.

Tabel 1 menunjukkan bahwa klon yang memiliki pertumbuhan paling jagur sampai umur 4 tahun di lokasi pengujian kebun Aek Pamienke adalah IRR 209 (47,5 $\mathrm{cm})$, IRR $211(51,0 \mathrm{~cm})$, IRR $215(49,5 \mathrm{~cm})$, IRR $216(48,0 \mathrm{~cm})$, IRR $217(47,5 \mathrm{~cm})$ dan IRR $220(47,0 \mathrm{~cm})$ dengan laju pertambahan lilit batang antara $10,8-11,6 \mathrm{~cm} / \mathrm{th}$. Pertumbuhan klon-klon tersebut 103 -
$108 \%$ terhadap klon pembanding PB 260 $(45,8 \mathrm{~cm})$ dan diperkirakan dapat dibuka sadap sebelum umur 4 tahun.

Di Kebun Serbangan, hanya klon IRR 220 yang tumbuh paling jagur dengan ukuran lilit batang pada umur empat tahun $42,8 \mathrm{~cm}$, atau $124 \%$ dibanding PB $260(34,5$ $\mathrm{cm})$ dan rata-rata pertambahan lilit batang $14,8 \mathrm{~cm} /$ th (Tabel 2). Menurut Aidi-Daslin (2005), klon jagur memiliki pertumbuhan awal cepat selama masa TBM dengan ratarata pertambahan lilit batang lebih dari 11 $\mathrm{cm} /$ th. 
Tabel 2. Pertumbuhan lilit batang klon IRR seri 200 di lokasi pengujian Serbangan Table 2. Girth growth of IRR 200 series clones at Serbangan trial location

\begin{tabular}{|c|c|c|c|c|}
\hline \multirow{2}{*}{$\begin{array}{l}\text { Klon } \\
\text { Clones }\end{array}$} & \multicolumn{3}{|c|}{$\begin{array}{c}\text { Lilit batang }(\mathrm{cm}) \text {, pada umur } \\
\text { Girth }(\mathrm{cm}) \text {, years }\end{array}$} & \multirow{2}{*}{$\begin{array}{c}\text { Pertambahan } \\
\text { lilit batang }(\mathrm{cm} / \mathrm{th}) \\
\text { Girth increment }(\mathrm{cm} / \mathrm{yr})\end{array}$} \\
\hline & $\begin{array}{l}2 \text { th } \\
2 y r\end{array}$ & $\begin{array}{l}3 \text { th } \\
3 y r\end{array}$ & $\begin{array}{l}4 \text { th } \\
4 y r\end{array}$ & \\
\hline IRR 205 & 14,2 & 25,6 & $37,6(109)$ & $11,7(116)$ \\
\hline IRR 206 & 11,2 & 22,7 & $30,0(87)$ & $9,4(93)$ \\
\hline IRR 207 & 15,5 & 25,0 & $38,0(110)$ & $11,3(112)$ \\
\hline IRR 208 & 14,5 & 27,2 & $38,4(111)$ & $12,0(119)$ \\
\hline IRR 209 & 13,2 & 20,8 & $35,0(101)$ & $10,9(108)$ \\
\hline IRR 211 & 15,3 & 22,0 & $36,6(106)$ & 10,7 (106) \\
\hline IRR 215 & 14,6 & 24,9 & $39,4(114)$ & $12,4(123)$ \\
\hline IRR 216 & 14,2 & 25,7 & $36,4(106)$ & $11,1(110)$ \\
\hline IRR 217 & 13,1 & 26,3 & $39,0(113)$ & $13,0(129)$ \\
\hline IRR 219 & 15,6 & 30,6 & $37,7(109)$ & $11,1(110)$ \\
\hline IRR 220 & 13,3 & 31,5 & $42,8(124)$ & $14,8(147)$ \\
\hline IRR 221 & 13,5 & 23,9 & $38,0(110)$ & $12,3(122)$ \\
\hline PB260 & 14,3 & 23,5 & $34,5(100)$ & $10,1(100)$ \\
\hline Rata-rata (average) & 14,0 & 25,4 & 37,2 & 11,6 \\
\hline Min. (minimum) & 11,2 & 20,8 & 30,0 & 9,4 \\
\hline Maks. (maximum) & 15,6 & 31,5 & 42,8 & 14,8 \\
\hline KK (coeff. of variation) & 8,57 & 12,17 & 8,05 & 11,80 \\
\hline
\end{tabular}

Angka-angka di dalam kurung adalah persentase terhadap PB 260

Figures in brackets are percentage of PB 260

\section{Stabilitas Pertumbuhan}

Stabilitas pertumbuhan klon yang diuji ditentukan oleh parameter indeks stabilitas. Dengan menghitung nilai parameter tersebut dapat dipilih klon-klon yang stabil (ataupun klon terbaik yang spesifik) pada dua lokasi pengujian. Klon yang tergolong paling stabil memiliki indeks stabilitas terendah. Stabilitas dari klon-klon yang diuji dengan pertumbuhan lilit batang umur empat tahun disajikan pada Tabel 3.

Nilai indeks stabilitas klon yang diuji berkisar 0,05 - 0,25. Klon IRR 220 tergolong stabil dan memiliki pertumbuhan yang jagur pada dua lokasi pengujian dengan rata-rata lilit batang dari dua lokasi sebesar 44,9 cm.
Klon yang paling stabil pertumbuhannya adalah IRR 208, tetapi tidak tergolong jagur (rata-rata lilit batang $39,9 \mathrm{~cm}$ ), sedangkan klon IRR 211 tergolong lebih spesifik lokasi, dengan rata-rata lilit batang tertinggi 51,0 $\mathrm{cm}$, terlihat paling adaptif di lokasi dengan curah hujan tinggi (Kebun Aek Pamienke).

Dari Tabel 3 dapat dilihat pertumbuhan lilit batang semua klon yang diuji lebih lambat di lokasi kebun Serbangan dengan curah hujan rendah dan jenis tanah hidromorfik yang relatif kurang subur dan semua klon memperlihatkan pertumbuhan lebih jagur di lokasi kebun Aek Pamienke dengan jenis tanah relatif lebih subur dan rata-rata curah hujan lebih tinggi. Hal ini menunjukkan pengaruh lokasi ternyata sangat signifikan serta tidak terlihat adanya 
Tabel 3. Rata-rata lilit batang dan indeks stabilitas klon IRR seri 200

Table 3. Girth average and stability index of IRR 200 series clones

\begin{tabular}{|c|c|c|c|c|c|}
\hline \multirow{2}{*}{$\begin{array}{l}\text { Klon } \\
\text { Clones }\end{array}$} & \multicolumn{3}{|c|}{$\begin{array}{l}\text { Lilit batang }(\mathrm{cm}) \text {, pada umur } 4 \text { tahun } \\
\text { Girth }(\mathrm{cm}) \text { at } 4 \text { years }\end{array}$} & \multicolumn{2}{|c|}{$\begin{array}{l}\text { Indeks stabilitas } \\
\text { Stability index }\end{array}$} \\
\hline & $\begin{array}{c}\text { Aek } \\
\text { Pamienke }\end{array}$ & Serbangan & $\begin{array}{l}\text { Rata -rata } \\
\text { Average }\end{array}$ & $\begin{array}{l}\text { Nilai } \\
\text { Value }\end{array}$ & $\begin{array}{l}\text { Urutan } \\
\text { Ranking }\end{array}$ \\
\hline IRR 205 & 46,7 & 37,6 & 42,2 & 0,15 & 7 \\
\hline IRR 206 & 42,6 & 30,0 & 36,3 & 0,25 & 13 \\
\hline IRR 207 & 45,7 & 38,0 & 41,9 & 0,13 & 4 \\
\hline IRR 208 & 41,4 & 38,4 & 39,9 & 0,05 & 1 \\
\hline IRR 209 & 47,5 & 35,0 & 41,3 & 0,21 & 11 \\
\hline IRR 211 & 51,0 & 36,6 & 43,8 & 0,23 & 12 \\
\hline IRR 215 & 49,5 & 39,4 & 44,5 & 0,16 & 8 \\
\hline IRR 216 & 48,0 & 36,4 & 42,2 & 0,19 & 9 \\
\hline IRR 217 & 47,5 & 39,0 & 43,3 & 0,14 & 6 \\
\hline IRR 219 & 46,1 & 37,7 & 41,9 & 0,14 & 5 \\
\hline IRR 220 & 47,0 & 42,8 & 44,9 & 0,07 & 2 \\
\hline IRR 221 & 44,6 & 38,0 & 41,3 & 0,11 & 3 \\
\hline PB260 & 45,8 & 34,5 & 40,2 & 0,20 & 10 \\
\hline $\begin{array}{l}\text { Rata -rata } \\
\text { Average }\end{array}$ & 46,4 & 37,2 & 41,8 & & \\
\hline
\end{tabular}

interaksi klon dan lokasi. Indikasi ini juga terlihat dari beberapa hasil penelitian yang menyimpulkan bahwa pertumbuhan beberapa klon karet ternyata lebih baik di daerah curah hujan sedang sampai dengan tinggi tetapi memiliki 2 - 3 bulan kering yang tegas (Aidi Daslin et al., 1997).

\section{Ketebalan Kulit dan Jaringan Pembuluh Lateks}

Beberapa sifat lain diketahui penting sebagai parameter seleksi klon, karena berkaitan secara langsung maupun tidak langsung terhadap potensi hasil lateks. Sifat tersebut diantaranya adalah tebal kulit, jumlah dan diameter saluran pembuluh lateks, sebagaimana disajikan pada Tabel 4.
Dari Tabel 4 diketahui bahwa rata-rata tebal kulit klon IRR seri 200 yang diuji cukup variatif, berkisar 5,2 - 7,2 mm. Klon yang memiliki tebal kulit tertinggi pada dua lokasi pengujian adalah IRR $211(7,2 \mathrm{~mm})$ dan IRR 220 (6,3 mm), masing-masing 136\% dan $119 \%$ terhadap klon pembanding PB 260 $(5,3 \mathrm{~mm})$. Rata-rata jumlah saluran pembuluh lateks berkisar 4,3 - 7,0. Klon yang memiliki jumlah saluran pembuluh lateks tertinggi adalah IRR $215(7,0)$ dan IRR $217(6,8)$, yaitu 105 - 108\% dibanding PB $260(6,5)$, sedangkan yang terendah klon IRR $205(4,3)$ dan IRR $221(4,8)$. Variabilitas klon dari diameter pembuluh lateks tergolong kecil $(\mathrm{KK}=3,32 \%)$, yaitu berkisar 23,75 26,57 $\mathrm{m \mu}$. Klon IRR 208, IRR 211, IRR 215 dan IRR 220 memiliki ukuran diameter pembuluh lateks yang tertinggi dengan kisaran $25,63-26,57 \mathrm{~m} \mu$ yaitu $98-101 \%$ terhadap klon pembanding PB $260(26,26 \mathrm{m \mu})$. 
Tabel 4. Tebal kulit dan pembuluh lateks klon IRR seri 200

Table 4. Bark thickness and latexvessel of IRR 200 series clones

\begin{tabular}{cccc}
\hline & Tebal kulit & \multicolumn{2}{c}{$\begin{array}{c}\text { Pembuluh lateks } \\
\text { Latex vessel }\end{array}$} \\
\cline { 3 - 4 } Clones & $\begin{array}{c}\text { Bark thickness } \\
(\mathrm{mm})\end{array}$ & $\begin{array}{c}\text { Jumlahsaluran } \\
\text { Rings }\end{array}$ & $\begin{array}{c}\text { Diameter } \\
\text { niameter } \\
(\mathrm{m} \mu)\end{array}$ \\
\hline IRR 205 & $5,7(108)$ & $4,3(66)$ & $23,75(90)$ \\
IRR 206 & $5,6(106)$ & $6,3(97)$ & $25,32(96)$ \\
IRR 207 & $5,5(104)$ & $6,3(97)$ & $25,39(97)$ \\
IRR 208 & $5,9(111)$ & $6,3(97)$ & $26,28(100)$ \\
IRR 209 & $5,6(106)$ & $6,3(97)$ & $25,32(96)$ \\
IRR 211 & $7,2(136)$ & $6,0(92)$ & $26,57(101)$ \\
IRR 215 & $6,1(115)$ & $7,0(108)$ & $25,94(99)$ \\
IRR 216 & $6,0(113)$ & $6,0(92)$ & $24,07(92)$ \\
IRR 217 & $5,6(106)$ & $6,8(105)$ & $25,00(95)$ \\
IRR 219 & $5,6(106)$ & $5,0(77)$ & $25,01(95)$ \\
IRR 220 & $6,3(119)$ & $5,5(85)$ & $25,63(98)$ \\
IRR 221 & $5,2(98)$ & $4,8(74)$ & $24,69(94)$ \\
PB260 & $5,3(100)$ & $6,5(100)$ & $26,26(100)$ \\
Ratarata (average) & 5,8 & 5,9 & 25,33 \\
Min. (minimum) & 5,2 & 4,3 & 23,75 \\
Maks. (maximum) & 7,2 & 7,0 & 26,57 \\
KK (coeff. ofvariation) & 8,9 & 13,6 & 3,32 \\
\hline Anga-anga & 58 &
\end{tabular}

Angka-angka di dalam kurung adalah persentase terhadap PB 260

Figures in brackets are percentage of PB 260

Ketahanan terhadap Penyakit Gugur Daun

Seleksi klon terhadap penyakit gugur daun Colletotrichum, Oidium, dan Corynespora sangat penting dilakukan, karena penyakit ini sangat mengganggu produktivitas tanaman karet. Berbagai hasil penelitian menunjukkan bahwa serangan yang berkelanjutan dapat menurunkan produktivitas sampai mencapai 40\% (Basuki et al., 1990; Thomanee et al., 1992). Evaluasi yang dilakukan pada tingkat pengujian di lapangan diharapkan dapat menghasilkan klon-klon yang memiliki ketahanan genetik kuat. Pada Tabel 5 terlihat bahwa klon IRR seri 200 yang diuji memiliki ketahanan yang tergolong agak resisten terhadap penyakit gugur daun Colletotrichum dengan intensitas serangan berkisar 20,67-26,56\%. Terhadap penyakit Oidium, seluruh klon yang diuji memiliki ketahanan yang tergolong resisten dengan intensitas serangan antara 16,24 20,66\%, kecuali klon IRR 211 dikategorikan agak resisten. Untuk ketahanan terhadap penyakit gugur daun Corynespora, klon IRR seri 200 yang diuji tergolong resisten dengan kisaran intensitas serangan $0,00-0,50 \%$.

\section{KESIMPULAN}

Dari hasil evaluasi keragaan TBM klon IRR seri 200 pada dua lokasi pengujian lanjutan diketahui bahwa klon IRR 220 memiliki pertumbuhan yang jagur dan stabil dengan rata-rata lilit batang mencapai 44,9 
Tabel 5. Intensitas serangan penyakit gugur daun pada klon IRR seri 200 di dua lokasi pengujian

Table 5. Attack intensity of leaffall diseases of IRR 200 series clones at two trial locations

\begin{tabular}{|c|c|c|c|c|c|c|}
\hline \multirow{2}{*}{$\begin{array}{l}\text { Klon } \\
\text { Clones }\end{array}$} & \multicolumn{2}{|c|}{ Colletotrichum } & \multicolumn{2}{|c|}{ Oidium } & \multicolumn{2}{|c|}{ Corynespora } \\
\hline & $\begin{array}{r}\text { Intensitas } \\
\text { Intensity }\end{array}$ & $\begin{array}{c}\text { Ketahanan } \\
\text { Resistance }\end{array}$ & $\begin{array}{r}\text { Intensitas } \\
\text { Intensity }\end{array}$ & $\begin{array}{l}\text { Ketahanan } \\
\text { Resistance }\end{array}$ & $\begin{array}{r}\text { Intensitas } \\
\text { Intensity }\end{array}$ & $\begin{array}{l}\text { Ketahanan } \\
\text { Resistance }\end{array}$ \\
\hline IRR 205 & 24,27 & AR & 18,06 & $\mathrm{R}$ & 0,00 & $\mathrm{R}$ \\
\hline IRR 206 & 20,67 & AR & 17,85 & $\mathrm{R}$ & 0,00 & $\mathrm{R}$ \\
\hline IRR 207 & 24,93 & AR & 17,18 & $\mathrm{R}$ & 0,00 & $\mathrm{R}$ \\
\hline IRR 208 & 23,31 & AR & 16,39 & $\mathrm{R}$ & 2,30 & $\mathrm{R}$ \\
\hline IRR 209 & 23,69 & AR & 18,46 & $\mathrm{R}$ & 0,00 & $\mathrm{R}$ \\
\hline IRR 211 & 23,20 & AR & 20,66 & AR & 0,00 & $\mathrm{R}$ \\
\hline IRR 215 & 22,49 & AR & 19,93 & $\mathrm{R}$ & 0,25 & $\mathrm{R}$ \\
\hline IRR 216 & 22,50 & AR & 17,88 & $\mathrm{R}$ & 0,00 & $\mathrm{R}$ \\
\hline IRR 217 & 26,56 & AR & 17,95 & $\mathrm{R}$ & 0,17 & $\mathrm{R}$ \\
\hline IRR 219 & 25,78 & AR & 16,24 & $\mathrm{R}$ & 0,00 & $\mathrm{R}$ \\
\hline IRR 220 & 20,74 & AR & 18,50 & $\mathrm{R}$ & 2,35 & $\mathrm{R}$ \\
\hline IRR 221 & 23,59 & AR & 17,35 & $\mathrm{R}$ & 0,50 & $\mathrm{R}$ \\
\hline PB260 & 18,96 & $\mathrm{R}$ & 14,41 & $\mathrm{R}$ & 0,00 & $\mathrm{R}$ \\
\hline
\end{tabular}

$\mathrm{AR}=$ agak resisten (moderately resistant)

$\mathrm{R}=$ resisten (resistant)

cm pada umur empat tahun, sedangkan klon IRR 211 tergolong paling jagur (ratarata lilit batang $51,0 \mathrm{~cm}$ ) tetapi hanya adaptif dikembangkan di lokasi dengan iklim yang lebih basah. Berdasarkan ketebalan kulit dan pembuluh lateks, klon-klon yang diprediksi berpeluang memiliki produktivitas yang baik adalah IRR 208, IRR 211, IRR 215, IRR 217, dan IRR 220. Semua klon yang diuji tergolong agak resisten sampai dengan resisten terhadap penyakit gugur daun Colletotrichum, Oidium, dan Corynespora.

\section{DAFTAR PUSTAKA}

Aidi-Daslin, I. Suhendry, dan R. Azwar. 1997. Produktivitas perkebunan karet dalam hubungannya dengan jenis klon dan agroklimat. Pros. Apresiasi Teknologi Peningkatan Produktivitas Lahan Perkebunan Karet, 201-215.
Aidi-Daslin. 2005. Kemajuan pemuliaan dan seleksi dalam menghasilkan kultivar karet unggul. Pros. Lok. Nas. Pemuliaan Tanaman Karet 2005, 2637.

Aidi-Daslin dan Sayurandi. 2006. Pengaruh interaksi genotipe dan lingkungan terhadap pertumbuhan dan produksi klon IRR seri 100 pada uji lanjutan. J. Penel. Karet, 24(2), 91-100.

Aidi-Daslin, S. Woelan, M. Lasminingsih, dan H. Hadi. 2009. Kemajuan pemuliaan dan seleksi tanaman karet di Indonesia. Pros. Lok. Nas. Pemuliaan Tanaman Karet 2009, 50-59.

Basuki, S. Pawirosoemardjo, U. Nasution, Sutardi, W. Sinulingga, dan A. Situmorang. 1990. Penyakit gugur daun Colletotrichum pada tanaman karet di Indonesia. Potensi, 
penyebaran dan penanggu-langannya. Pros. Lok. Nas. Pemuliaan Tanaman Karet 1990, 268-295.

Pawirosoemardjo. 1999. Epidemiologi dan Pengendalian Penyakit Gugur Daun Corynespora dan Colletotrichum Secara Terpadu. Laporan Hasil Penelitian. Proyek Penelitian Karet Sungei Putih, Medan.

Steel and Torrie. 1982. Principles and Procedures of Statistics. A Biometrical Approach. McGraw-Hill International Book Company.

Simmond, N.W. 1989. Rubber Breeding. In: Webster C.C. and Baulkwill, W.J. (eds.). Rubber Longman Group, London.
Tan, H. 1987. Strategics in Rubber Tree Breeding. In : Improve-ment of Vegetatively Pro-pagated Crop (A.J. Abbot and R.K. Attein, eds.), 27-29.

Thomanee A., S. Chimsathit, and S. Sookmark. 1992. Progress report on the 1974 Multilateral Exchange Clone Trials. ANRPC Report of the First Meeting of Plant Breeders. Hat Yai, Thailand.

Woelan, S., Aidi-Daslin, M. Lasminingsih, dan I. Suhendry. 2009. Evaluasi keragaan klon IRR seri 200 dan 300 pada tahap pengujian. Pros. Lok. Nas. Pemuliaan Tanaman Karet 2009, 84106. 
Lampiran 1. Deskripsi lokasi pengujian lanjutan klon karet IRR seri 200 Appendix 1. Description of further trial locations of IRR 200 series rubber clones

\begin{tabular}{|c|c|c|c|}
\hline \multirow{2}{*}{ No. } & \multirow{2}{*}{$\begin{array}{l}\text { Keterangan } \\
\text { Remarks }\end{array}$} & \multicolumn{2}{|l|}{$\begin{array}{c}\text { Lokasi } \\
\text { Locations }\end{array}$} \\
\hline & & Serbangan & Aek Pamienke \\
\hline \multirow[t]{2}{*}{1.} & Tahun tanam & Desember 2005 & November 2005 \\
\hline & Planting year & & \\
\hline \multirow[t]{2}{*}{2.} & Jarak tanam & $3,8 \times 5,5 \mathrm{~m}$ & $3,0 \times 6,5 \mathrm{~m}$ \\
\hline & Planting distance & & \\
\hline \multirow[t]{2}{*}{3.} & Luas plot & 10 baris (rows) x 55 pohon (trees) & 12 baris (rows) $\times 50$ pohon (trees \\
\hline & Plot size & & \\
\hline \multirow[t]{2}{*}{4.} & Luas percobaan & 18,4 hektar (hectare) & 20 hektar (hectare) \\
\hline & Total area & & \\
\hline \multirow[t]{2}{*}{5.} & Bahan tanam & Polibeg dua payung & Polibeg dua payung \\
\hline & Planting material & Twawhorl polybag & Twawhorl polybag \\
\hline \multirow[t]{2}{*}{6.} & Penutup tanah & Mucuna bracteata & Mucuna bracteata \\
\hline & Cover crops & & \\
\hline \multirow[t]{2}{*}{7.} & Topografi & Datar (flat) & Datar (flat) \\
\hline & Topography & & \\
\hline \multirow[t]{2}{*}{8.} & Tinggtempat & 10mdpl (abovesee level) & $145 \mathrm{mdpl}($ above see level) \\
\hline & Elevation & & \\
\hline \multirow[t]{2}{*}{9.} & Jenis tanah & Entisol & Ultisol \\
\hline & Soil types & & \\
\hline \multirow[t]{2}{*}{10.} & Tekstur tanah & Lempung berpasir & Lempung liat berpasir \\
\hline & Soil textures & Sandy loam & Sandy clay loam \\
\hline \multirow[t]{2}{*}{11.} & Rata-rata curah hujan & $1625 \mathrm{~mm} /$ th $(\mathrm{mm} / \mathrm{yr})$ & $3036 \mathrm{~mm} /$ th $(\mathrm{mm} / \mathrm{yr})$ \\
\hline & Average rainfall & & \\
\hline \multirow[t]{2}{*}{12.} & Jumlah hari hujan & $70-110$ hari/th (days/yr) & 120-170hari/th (days/yr) \\
\hline & Rainday number & & \\
\hline \multirow[t]{2}{*}{13.} & Jumlah bulan kering & 3-4 bulan/th (months/yr) & 2-3 bulan /th (months/yr) \\
\hline & Dry month number & & \\
\hline
\end{tabular}

Lampiran 2. Silsilah klon IRR seri 200

Appendix 2. Parentage of IRR 200 series clones

\begin{tabular}{ccc}
\hline No. & $\begin{array}{c}\text { Klon } \\
\text { Clones }\end{array}$ & $\begin{array}{c}\text { Silsilah } \\
\text { Parentage }\end{array}$ \\
\hline 1 & IRR 205 & PB 260 X BPM 101 \\
2 & IRR 206 & PB 260 X BPM 101 \\
3 & IRR 207 & BPM 24 X IAN 873 \\
4 & IRR 208 & BPM 24 X IAN 873 \\
5 & IRR 209 & PB 260 X F 4542 \\
6 & IRR 211 & PB 260 X IAN 873 \\
7 & IRR 215 & PB 260 X IAN 873 \\
8 & IRR 216 & PB 260 X F 4542 \\
9 & IRR 217 & PB 260 X F 4542 \\
10 & IRR 219 & PB 260 X IAN 873 \\
11 & IRR 220 & PB 260 X IAN 873 \\
12 & IRR 221 & IAN $873 \times$ PB 260
\end{tabular}

